\title{
Dosage of 2,6-Bis (1.1-Dimethylethyl)-4-Methylphenol (BHT) in the Plant Extract Mesembryanthemum crystallinum
}

\author{
Bouftira Ibtissem, Mgaidi Imen, and Sfar Souad \\ Laboratory of Galenic Pharmacy, Faculty of Pharmacy of Monastir, Rue Ibn Sina, Monastir 5000, Tunisia \\ Correspondence should be addressed to Bouftira Ibtissem, ibtissem.bouftira@laposte.net
}

Received 21 September 2010; Accepted 19 December 2010

Academic Editor: J. Birchler

Copyright ( $) 2010$ Bouftira Ibtissem et al. This is an open access article distributed under the Creative Commons Attribution License, which permits unrestricted use, distribution, and reproduction in any medium, provided the original work is properly cited.

A naturally occurring BHT was identified in the leaves of the halophyte plant Mesembryanthemum crystallinum. This phenol was extracted in this study by two methods at the different plant growth stages. One of the methods was better for BHT extraction; the concentration of this phenol is plant growth stage dependent. In this study, the floraison stage has the highest BHT concentration. The antioxidant activity of the plant extract was not related to BHT concentration. The higher antioxidant activity is obtained at seedlings stage.

\section{Introduction}

The 2,6-bis (1.1-dimethylethyl)-4-methylphenol (BHT), also known as butylhydroxytoluene, is a lipophilic (fat soluble) organic compound that is primarily used as an antioxidant food additive as well as in cosmetics, pharmaceuticals, jet fuels, rubber, petroleum products, and electrical transformer oil [1]. BHT is prepared by the reaction of p-cresol (4-methylphenol) with isobutylene (2methylpropene) catalysed by sulfuric acid [2]. A naturally occurring BHT was identified in the halophyte plant Mesembryanthemum crystallinum [3]. The species Mesembryanthemum crystallinum (family: Aizoaceae, order: Caryophyllales), also termed the common ice plant, has emerged as a model organism in plant molecular physiology [4]. The plant's rise to relative fame started with the serendipitous discovery of a stress-inducible switch from C3 photosynthesis to Crassulacean acid metabolism (CAM) $[5,6]$. A second major area of interest centres on the plant's extreme stress tolerance, particularly tolerance to high salinity. The plant thrives in coastal area under climatic conditions characterized by short, cool, moist winters and long dry summers [7]. Mesembryanthemum crystallinum shows five distinct growth phases during its life cycle (i.e., germinating seedlings, juvenile, adult, flowering, and seed forming) [8]. The plant is demulcent and diuretic. Historically, physicians used leaf juice to soothe inflammation of the mucous membranes of the respiratory or urinary system. In Europe, the fresh juice has been used to treat water retention and painful urination and to soothe lung inflammation [9].

During normal metabolism, plants generate reactive oxygen species (ROS), including superoxide radical $\left(\mathrm{O}_{2}{ }^{-}\right)$, hydrogen peroxide $\left(\mathrm{H}_{2} \mathrm{O}_{2}\right)$, hydroxyl radical $(\mathrm{HO} \bullet)$, and singlet oxygen $\left(\mathrm{O}_{2}{ }^{1}\right)$ [10]. ROS are overproduced in plants under stress, including drought and desiccation, salt stress, chilling, heat shock, heavy metals, ultraviolet radiation, air pollutants, such as ozone and $\mathrm{SO}_{2}$, mechanical stress, nutrient deprivation, pathogen attack and high light stress [11].

To mitigate the oxidative damage initiated by ROS, plants have developed a complex antioxidative system [12]. In the halophyte plant Mesembryanthemum crystallinum, high photosynthetic active radiation and ultraviolet irradiance induce the accumulation of flavonoids [13]. Abiotic stress particularly salinity induces BHT accumulation in Mesembryanthemum crystallinum leaves [3].

The aim of this study is to select a method for a better extraction of BHT from the leaves of the halophyte plant Mesembryanthemum crystallinum.

\section{Material and Methods}

2.1. Plant Material. The leaves of the halophyte plant Mesembryanthemum crystallinum were collected from their 


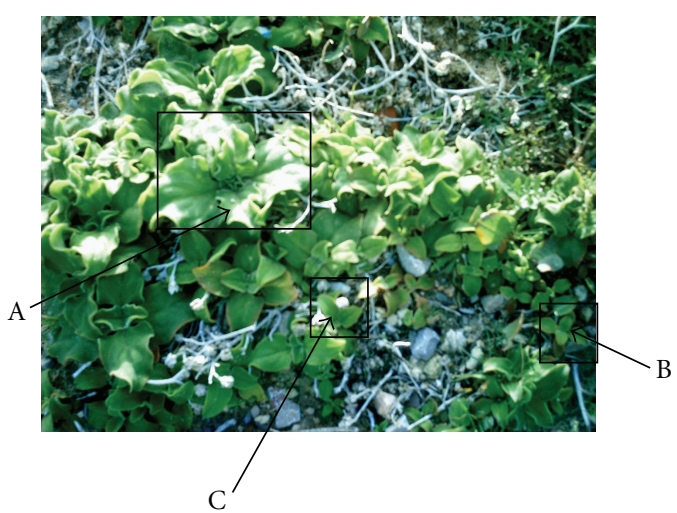

FIGURE 1: Mesembryanthemum crystallinum at December 2008 with three growth stages. (a) Adult; (b) juvenile; (c) seedlings.

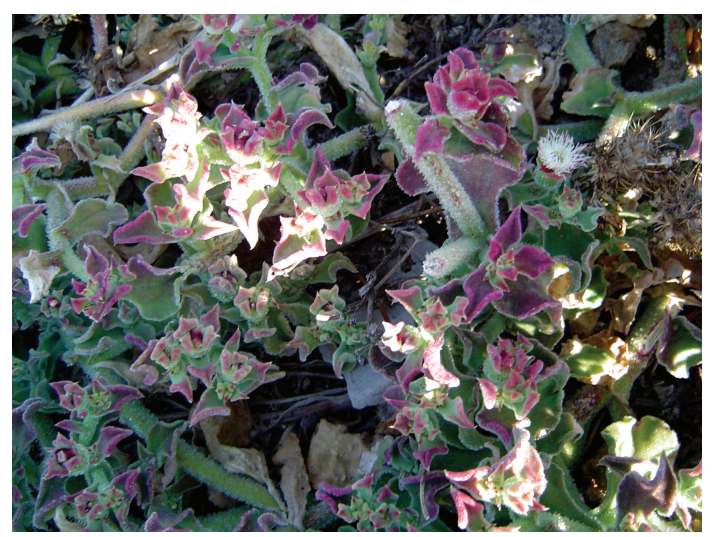

Figure 2: Mesembryanthemum crystallinum at June 2007 with floraison stage.

natural biotope in the two periods June 2007 and December 2008 (Figures 1 and 2). Plant leaves were taken immediately to the laboratory in a sterile tissue paper.

\subsection{Extraction}

Method 1 (Sanches et al. [14]). $10 \mathrm{~g}$ of plant leaves were mixed in the presence of acetonitrile $(2 \mathrm{~mL})$ and hexane $(20 \mathrm{~mL})$, after centrifugation 10 minat $1,036 \times \mathrm{g}$, organic fraction was suppressed. Extraction was repeated once in the presence of hexane $(20 \mathrm{~mL})$. The fraction in the presence of hexane was suppressed (rotavapo, $40^{\circ}$ ). The BHT concentration of the extract was determined in the different plant growth stages in parallel with the antioxidant activity.

Method 2 (Bouftira et al. [3]). $25 \mathrm{~g}$ of plant leaves were mixed in the presence of methanol $80 \%$ containing ascorbic acid $50 \mathrm{mM}$. After centrifugation, $14000 \times \mathrm{g}$, at $4^{\circ} \mathrm{C}$, the supernatant was collected.

2.3. Antiradical Activity. Free radical scavenging activity of plant extract was determined by using a stable free radical, (1,1-diphenyl-2-picryl-hydrazyl) DPPH [15]. DPPH solution was prepared at a concentration of $0.024 \mathrm{mg} / \mathrm{mL}$ in

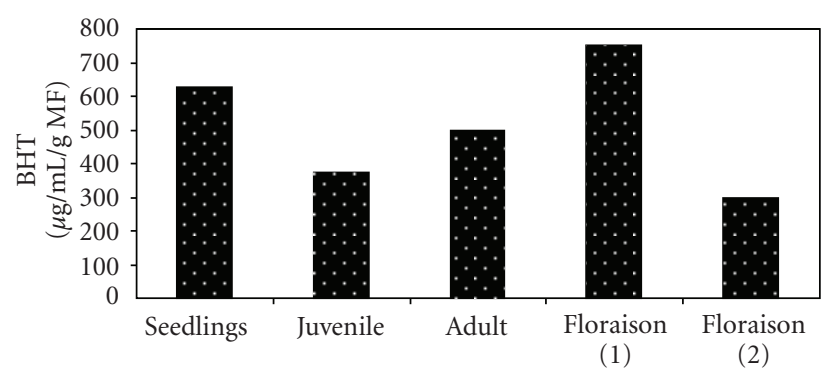

Figure 3: BHT content ( $\mu \mathrm{g} / \mathrm{mL} / \mathrm{g}$ MF) in the plant leaves at different growth stages.

ethanol. During assay, $1 \mathrm{~mL}$ of the crude extract was mixed with $1 \mathrm{~mL}$ DPPH solution. The mixture was incubated in the room temperature for $30 \mathrm{~min}$; absorbance was recorded at $517 \mathrm{~nm}$ (Cam spec M230/330 UV visible spectrophotometer, UK). Synthetic butylated hydroxytoluene (BHT) was used as a standard for the investigation of the antiradical activity. The percentage of remaining DPPH (\%DPPH REM) at the steady state was determined as follows: \%DPPH REM = $100 \mathrm{CDPPH} / \mathrm{CDPPH}(t=0)$, where $\mathrm{CDPPH}(t=0)$ is the initial DPPH concentration and CDPPH is the DPPH concentration at the steady state.

2.4. Chromatography. A Hewlett Packard 1100 analytical HPLC was used with a gradient elution method; within $2 \mathrm{~min}$, the mobile phase was acetonitrile-water $(65+35)$, after which the acetonitrile was raised to $100 \%$ within $15 \mathrm{~min}$. The total runtime of each analysis was $30 \mathrm{~min}$ to ensure cleaning of the column between samples. The flow rate was $1 \mathrm{~mL} / \mathrm{min}$ and the injection volume $20 \mu \mathrm{L}$. BHT was identified by comparison of its retention time and UV spectra with those of an injected pure standard in the HPLC method.

\section{Results}

3.1. HPLC Analysis. The concentration of BHT was determined in $\mu \mathrm{g} / \mathrm{mL} / \mathrm{g}$ of fresh leaves (Figure 1). BHT spectra were detected at $280 \mathrm{~nm}$ by analytical HPLC (Figure 2); the different spectra were compared between the plant growth stage and the BHT standard $(10 \mathrm{mg} / \mathrm{mL})$.

3.2. Antiradical Activity of BHT Extracts. The results (Figure 3), by using Method 1 of extraction showed that the seedlings stage has the highest antiradical activity $(65,24 \pm 0,27)$.

Figure 4 showed the comparison of antiradical activity between the two methods (Method 1 and 2). At the same plant growth stage (floraison), the extraction by Method 1 has higher antiradical activity $(51 \pm 0,82)$ in comparison with Method $2(32,33 \pm 2,05)$.

\section{Discussion}

The results showed that Mesembryanthemum crystallinum extract at seeds stage has the highest BHT concentration. At 


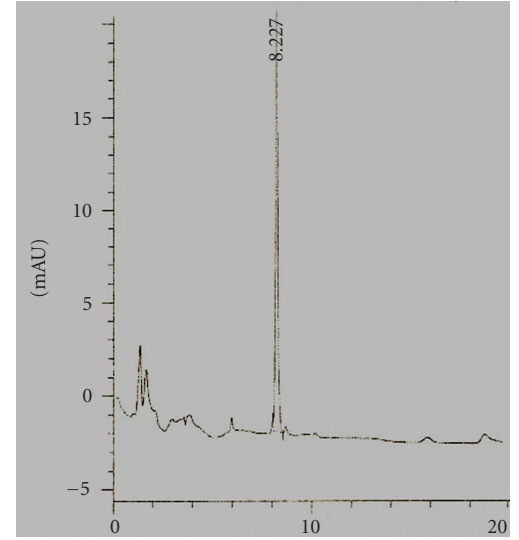

(a)

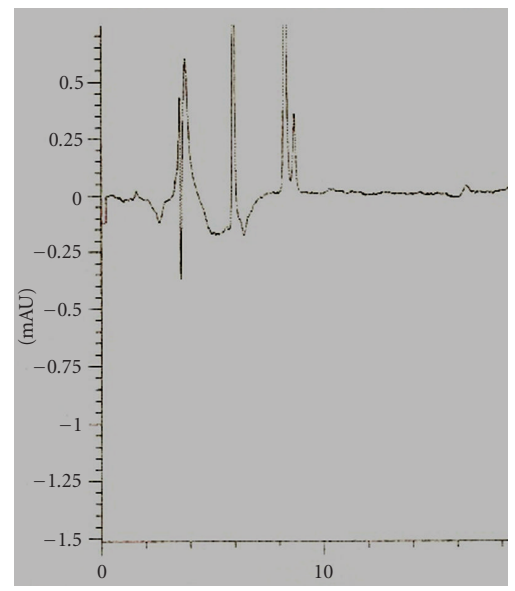

(c)

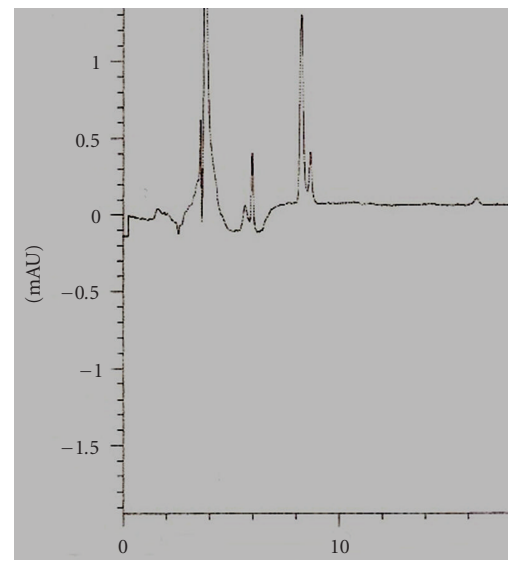

(e)

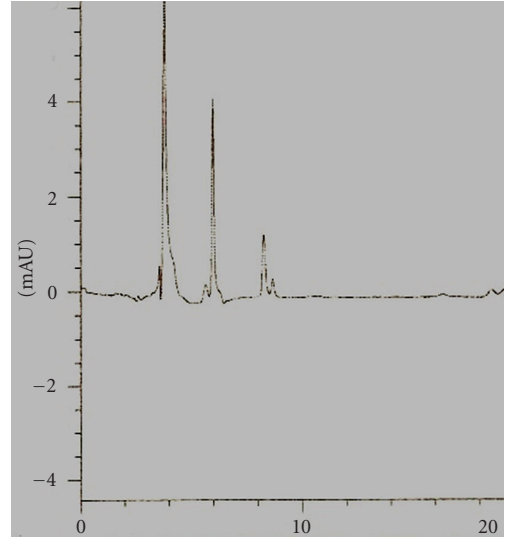

(b)

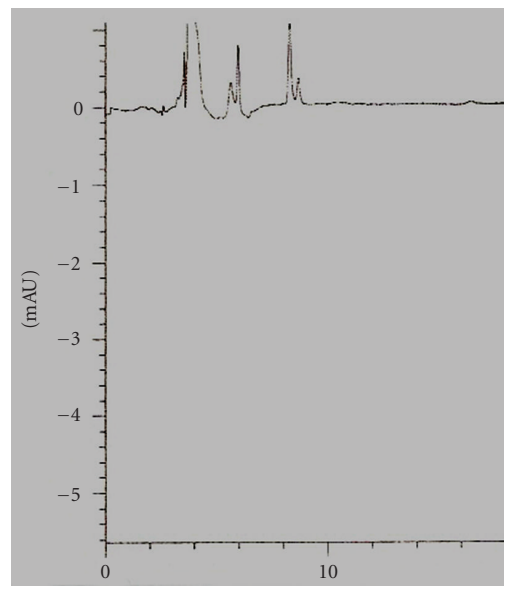

(d)

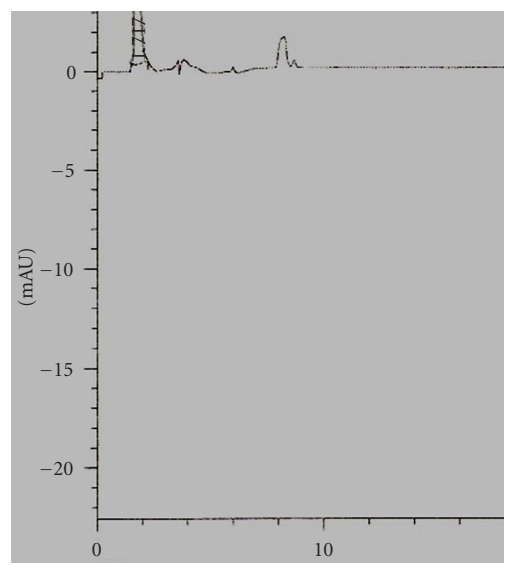

(f)

FIGURE 4: BHT spectra: (a) standard (10 mg/ml); (b) Seedlings extract; (c) Juvenile extract; (d) Adult extract; (e) Floraison extract by Method 1; (f) Floraison extract by Method 2.

this period, the plant leaves are purple resulting from tolerance to stress of environment. In the seeds stage, the plant is exposed to solar radiation. The light stress can attribute in part to stimulate the plant for the synthesis of BHT. It was proved that $M$. crystallinum after irradiation with high light irradiance displays a rapid cell-specific accumulation of plant secondary metabolites in the upper leaf epidermis: a phenomenon that is not detectable with salt or drought stress. M. crystallinum induced betacyanin formation and simultaneous formation of flavonol conjugates [13].

The results of this study showed also that the method of extraction influences the yield of BHT. The method 


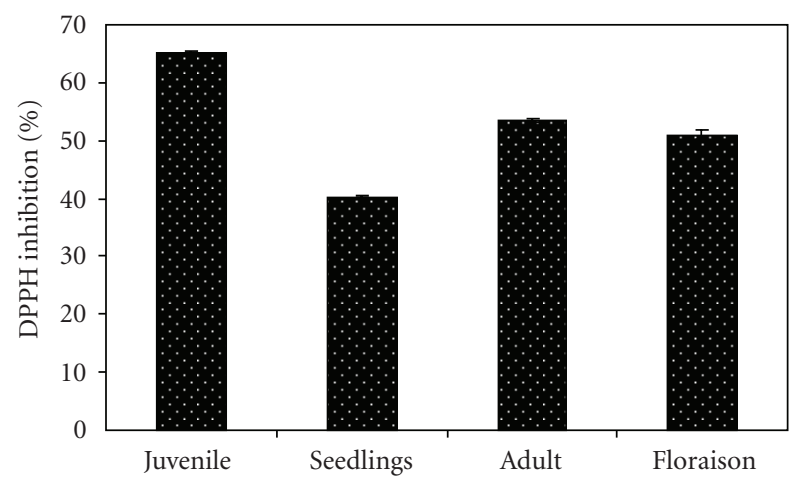

Figure 5: Comparison of antiradical activity in the different plant extracts by Method 1 extraction.

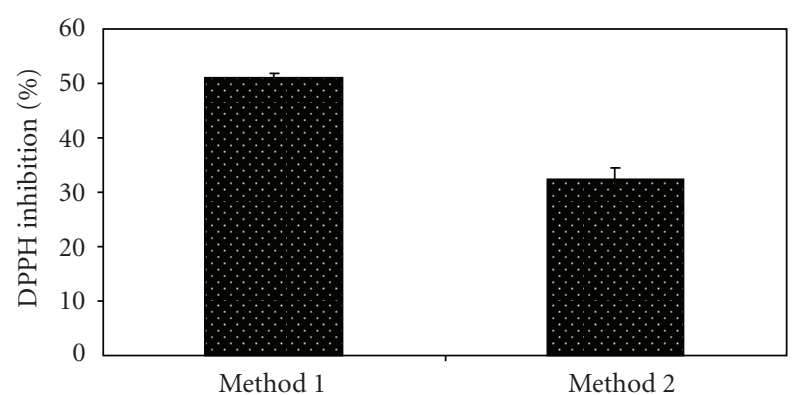

FIgure 6: Comparison of the antiradical activity between the two methods of BHT extraction at the same plant growth stage.

using hexane and acetonitrile is better than that using methanol $80 \%$ for BHT extraction. Different solvent systems have been used for the extraction of polyphenols from plant material [16]. Extraction yield is dependent on the solvent and method of extraction [17]. The extraction method must allow complete extraction of the compounds of interest, and it must avoid their chemical modification [18]. Water and aqueous mixture of ethanol, methanol, and acetone are commonly used for plant extraction [19]. The purple-coloured DPPH is a stable free radical, which is reduced to a,a-diphenyl-b-picrylhydrazine (yellow coloured) by reacting with an antioxidant. Antioxidants interrupt free radical chain oxidation by donating hydrogen from hydroxyl groups to form a stable end product, which does not initiate or propagate further oxidation of lipids [20].

The data obtained showed that the antioxidant activity was higher at seedlings stage in comparison with the other plant stages. This activity is not the result of BHT concentration. In fact, $M$. crystallinum accumulates more BHT at floraison stage in comparison with seedlings stage. The plant accumulates, at seedlings stage, other antioxidant compounds which work in association with BHT.

At the floraison stage, this study also showed that the method of extraction is in relation with the antioxidant activity. The method using hexane and acetonitrile $(51 \pm 0,82)$ for extraction showed higher antioxidant activity than those using methanol $80 \%(32,33 \pm 2,05)$. Many medicinal plants are investigated for their antioxidant activity in relation with the methods of extraction and the solvent used.

It was found that higher amounts of polyphenols and anthocyanins are found in methanol and ethanol extracts than in water extracts. It means that they are more efficient in cell walls which have unpolar character and cause polyphenols to be released from cells. More useful explanation for the decrease is ascribed to the enzyme polyphenol oxidase, which degrades polyphenols in water extracts whereas in methanol and ethanol they are inactive.

In conclusion, the results of this study are very important; we obtained a better method for BHT extraction. The concentration of this phenol is dependent on the plant growth stage. In fact, the floraison stage has the highest BHT concentration. The antioxidant activity of the plant extract is not related to BHT concentration. The higher antioxidant activity is obtained at seedlings stage.

\section{References}

[1] F. D. D. De Seguridad, "Ficha de Datos De Seguridad," Transformador, vol. 64, p. 1, 2008.

[2] H. Fiege, H. W. Voges, T. Hamamoto et al., "Phenol derivatives," in Ullmann's Encyclopedia of Industrial Chemistry, Wiley-VCH, Weinheim, Germany, 2002.

[3] I. Bouftira, C. Abdelly, and S. Sfar, "Identification of a naturally occurring 2, 6-bis (1.1-dimethylethyl)-4- methylphenol from purple leaves of the halophyte plant Mesembryanthemum crystallinum," African Journal of Biotechnology, vol. 6, no. 9, pp. 1136-1139, 2007.

[4] P. Adams, D. E. Nelson, S. Yamada et al., "Growth and development of Mesembryanthemum crystallinum (Aizoaceae)," New Phytologist, vol. 138, no. 2, pp. 171-190, 1998.

[5] K. Winter and D. J. von Willert, "NaCl-induzierter Crassulaceen saürestoffwechsel bei Mesembryanthemum crystallinum," Zeitschrift Fur Pflanzenphysiologie, vol. 67, pp. 166170, 1972.

[6] J. C. Cushman and H. J. Bohnert, "Crassulacean acid metabolism: molecular genetics," Annual Review of Plant Biology, vol. 50, pp. 305-332, 1999.

[7] A. J. Bloom and J. H. Troughton, "High productivity and photosynthetic flexibility in a CAM plant," Oecologia, vol. 38, no. 1, pp. 35-43, 1979.

[8] H. J. Bohnert and J. C. Cushman, "The ice plant cometh: lessons in abiotic stress tolerance," Journal of Plant Growth Regulation, vol. 19, no. 3, pp. 334-346, 2000.

[9] S. Foster, C. Hobbs, and R. T. Peterson, A Field Guide to Western Medicinal Plants and Herbs, Peterson Field Guides, Mifflin, Pa, USA, 2002.

[10] Z. Qiu-Fang, L. Yuan-Yuan, P. Cai-Hong, L. Cong-Ming, and W. Bao-Shan, "NaCl enhances thylakoid-bound SOD activity in the leaves of $\mathrm{C}_{3}$ halophyte Suaeda salsa L," Plant Science, vol. 168, no. 2, pp. 423-430, 2005.

[11] R. D. Allen, "Dissection of oxidative stress tolerance using transgenic plants," Plant Physiology, vol. 107, no. 4, pp. 10491054, 1995.

[12] A. D. De Azevedo Neto, J. T. Prisco, J. Enéas-Filho, C. E. B. D. Abreu, and E. Gomes-Filho, "Effect of salt stress on antioxidative enzymes and lipid peroxidation in leaves and roots of salt-tolerant and salt-sensitive maize genotypes," Environmental and Experimental Botany, vol. 56, no. 1, pp. 8794, 2006. 
[13] M. Ibdah, A. Krins, H. K. Seidlitz, W. Heller, D. Strack, and T. Vogt, "Spectral dependence of flavonol and betacyanin accumulation in Mesembryanthemum crystallinum under enhanced ultraviolet radiation," Plant, Cell and Environment, vol. 25, no. 9, pp. 1145-1154, 2002.

[14] A. Sanches-Silva, J. M. Cruz, R. Sendón-García, and P. PaseiroLosada, "Determination of butylated hydroxytoluene in food samples by high-performance liquid chromatography with ultraviolet detection and gas chromatography/mass spectrometry," Journal of AOAC International, vol. 90, no. 1, pp. 277283, 2007.

[15] M. S. Blois, "Antioxidant determinations by the use of a stable free radical," Nature, vol. 181, no. 4617, pp. 1199-1200, 1958.

[16] M. Pinelo, M. Rubilar, J. Sineiro, and M. J. Núñez, "Extraction of antioxidant phenolics from almond hulls (Prunus amygdalus) and pine sawdust (Pinus pinaster)," Food Chemistry, vol. 85, no. 2, pp. 267-273, 2004.

[17] A. H. Goli, M. Barzegar, and M. A. Sahari, "Antioxidant activity and total phenolic compounds of pistachio (Pistachia vera) hull extracts," Food Chemistry, vol. 92, no. 3, pp. 521525, 2005.

[18] Y. Zuo, H. Chen, and Y. Deng, "Simultaneous determination of catechins, caffeine and gallic acids in green, oolong, black and pu-erh teas using HPLC with a photodiode array detector," Talanta, vol. 57, no. 2, pp. 307-316, 2002.

[19] T. Sun and C.-T. Ho, "Antioxidant activities of buckwheat extracts," Food Chemistry, vol. 90, no. 4, pp. 743-749, 2005.

[20] E. R. Sherwin, "Oxidation and antioxidants in fat and oil processing," Journal of the American Oil Chemists' Society, vol. 55, no. 11, pp. 809-814, 1978. 

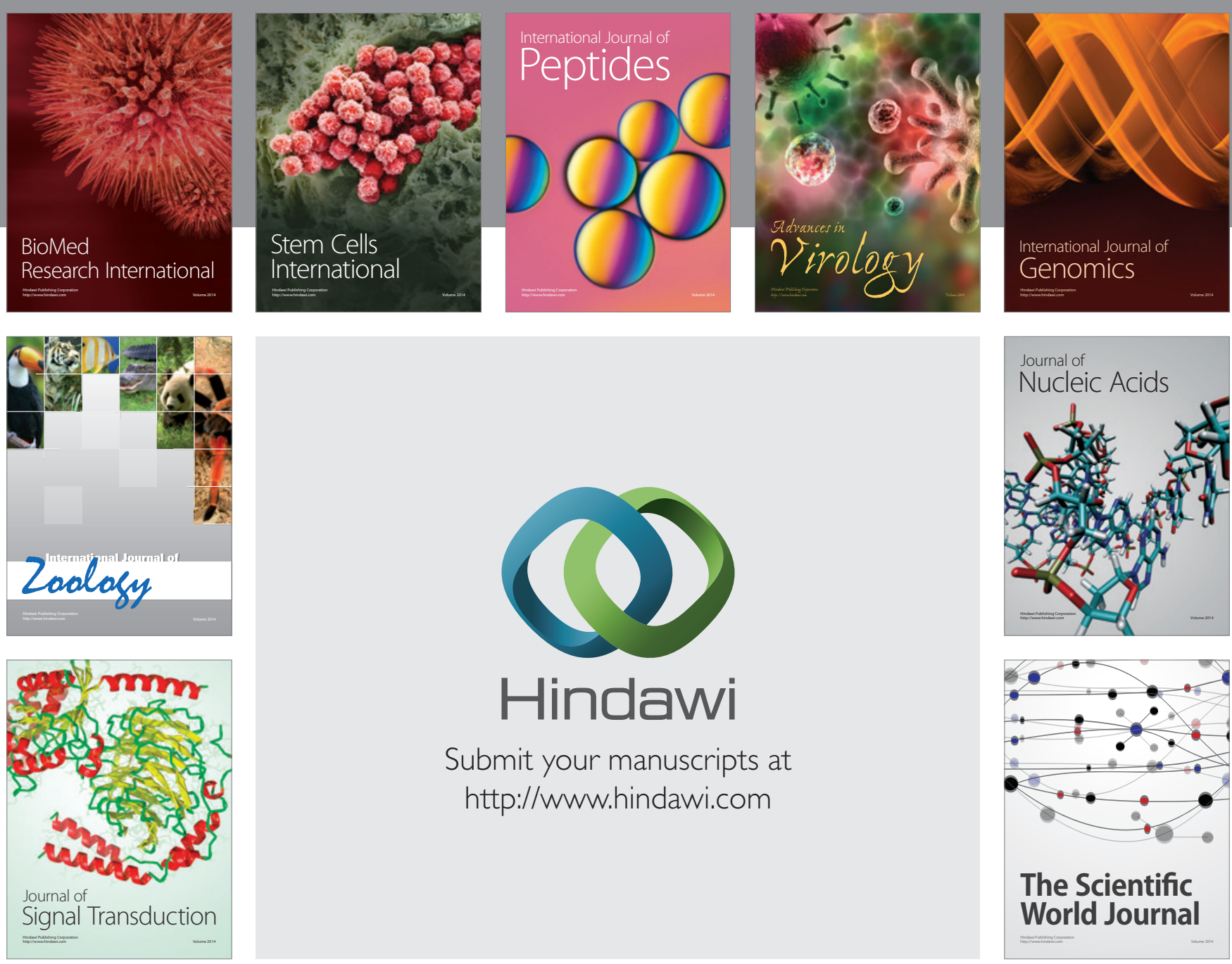

Submit your manuscripts at

http://www.hindawi.com
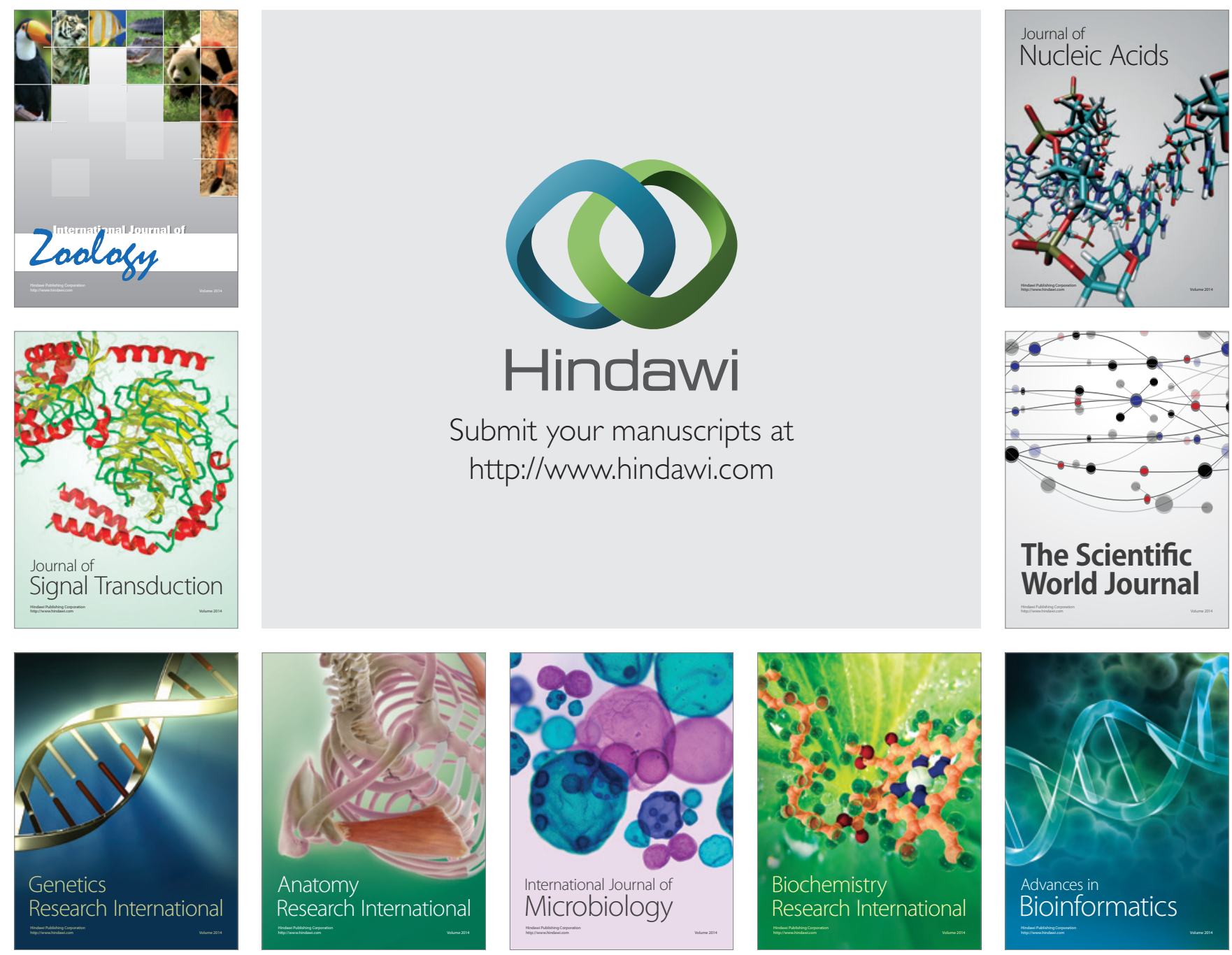

The Scientific World Journal
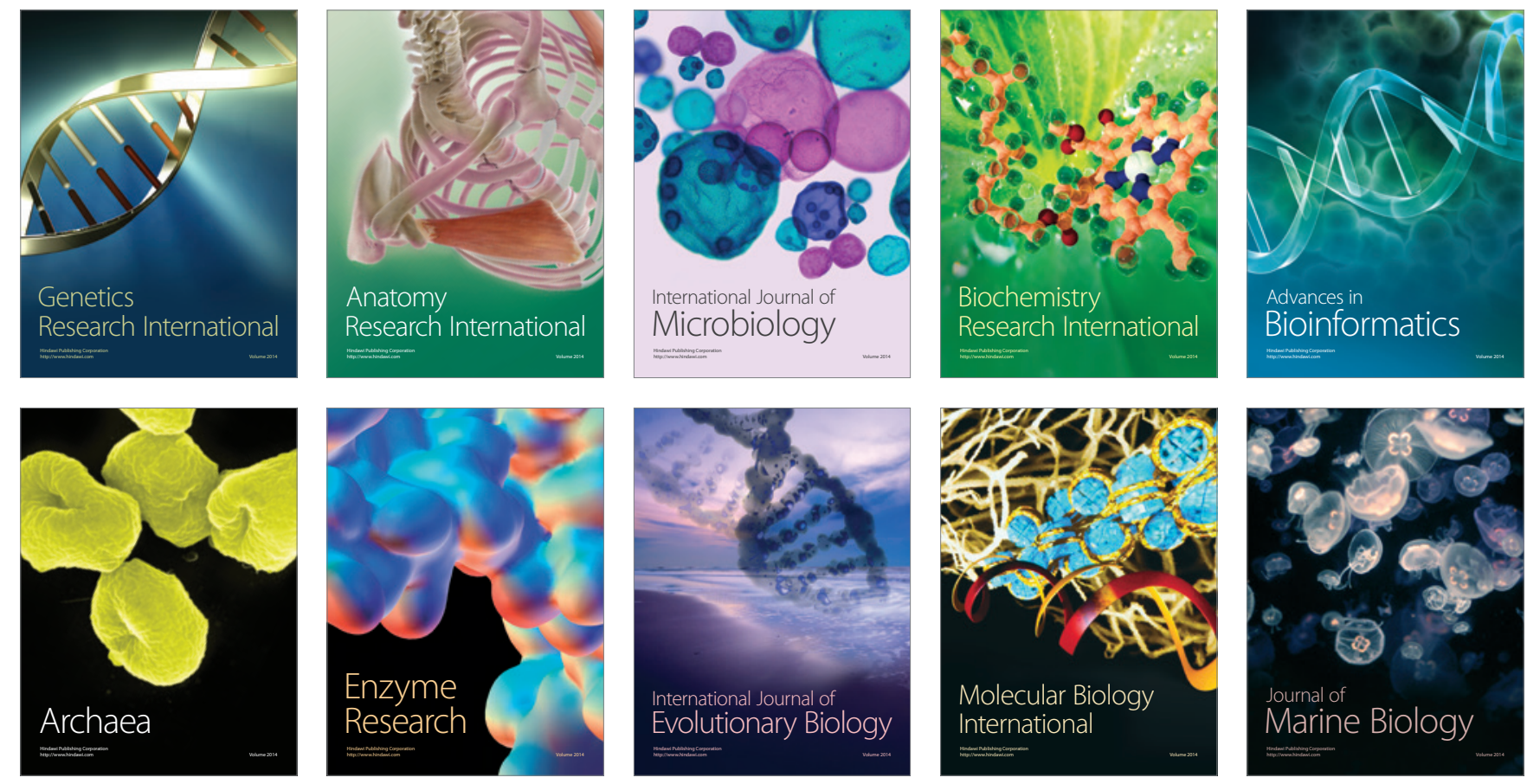